\title{
A SOCIOLOGIA PÚBLICA E O FIM DA SOCIEDADE ${ }^{1}$
}

\author{
Alain Touraine*
}

\begin{abstract}
Partindo da constatação que a pesquisa sociológica não corresponde mais à sua definição clássica e que, consequentemente, o momento de a comunidade acadêmica superar a contradição entre a sociologia profissional e a sociologia crítica chegou, o autor discute alguns pontos centrais da proposta de Burawoy acerca da sociologia pública. Por meio do recurso a experiências provenientes da vida intelectual europeia, estadunidense e latino-americana, o autor, neste artigo esforça-se em relacionar a sociologia pública ao processo político mais geral de reconhecimento dos direitos dos atores sociais, capaz de organizar o campo no interior do qual uma "sociologia geral dos atores" possa florescer e se desenvolver. O autor constata que existem tempos em que a demanda por teorização é mais urgente; e outras épocas em que a crítica social tem prioridade. Ele conclui que, se a comunidade sociológica ainda afirma a necessidade de identificar os principais problemas sociais contemporâneos, então a combinação da sociologia pública com a sociologia profissional se faz mais necessária.

PALAVRAS-CHAVE: sociologia do conhecimento, sociologia acadêmica, direitos sociais, atores políticos, crítica social.
\end{abstract}

A proposição de uma sociologia pública, formulada por Burawoy (2005), parte de um sentimento repentino sobre nosso duplo fracasso: é chegado o momento de superarmos a contradição insustentável entre a sociologia profissional e a sociologia crítica. Ambas, quando sozinhas, são igualmente irrelevantes para nossas expectativas. A primeira, a sociologia profissional, que alcançou sua forma mais acabada no sistema construído por Talcott Parsons (1977; 1991), definhou rapidamente no decorrer dos anos 1970, quando a Guerra do Vietnã e as campanhas pelos direitos civis dos negros (denominados afro-americanos) levaram à profunda rejeição da ideia de sistema social: um conceito que parecia dissimular os processos de dominação, conquista e repressão que penetravam cada vez mais profundamente em todos os setores da vida social. Hoje, é

* Professor da École des Hautes Études en Sciences Sociales, Paris.

Centre d'Analyse et d'Intervention Sociologique. cadiscom@ehess.fr

${ }^{1}$ Artigo originalmente publicado em Clawson, Dan et al. Public sociology: fifteen eminent sociologists debate politics and the profession in the twenty-first century. Berkeley: University of California Press, 2007. Traduzido por Fernando Rogério Jardim. Revisão dos organizadores do dossiê. impossível imaginarmos um movimento de resgate ou de retorno aos conceitos de Parsons (1977; 1991); a não ser que permaneçamos dentro das instituições acadêmicas - as mesmas que protegem alguns professores universitários da desordem que vem do mundo exterior.

Já a segunda, a sociologia crítica, vem perdendo ainda mais rapidamente sua influência, não apenas porque ela foi incapaz de manter alianças com o "espectro socialista" (russo, cubano, chinês), mas também porque ela foi prejudicada pelo seu próprio determinismo social - um determinismo estreito, que rejeitara qualquer possibilidade de os movimentos políticos ou sociais destruírem um sistema de dominação que determina até as categorias da representação que os atores usam. O melhor exemplo dessa autodestruição da sociologia crítica é o amplo sucesso obtido, na América Latina, pela forma mais radical de teoria da dependência. Se "nada pode ser feito", resta-nos apenas denunciar a dominação estrangeira ou sacrificarmos nossas vidas - tal como o fez Che Guevara.

Alguns pensadores e escritores preguiçosos acreditam que essas dificuldades possam ser su- 
peradas pela redução dos níveis de análise. Eles apontam que a vida diária e o discurso ordinário oferecem exemplos concretos de instâncias onde a sociologia profissional e o pensamento crítico estão combinados, da mesma forma que nossos julgamentos são tanto pragmáticos como normativos. Mas nós não podemos resolver o problema ao dissolvê-lo em declarações atenuadas.

A proposta de Burawoy (2005) poderia ser descrita como um convite para buscarmos soluções totalmente diferentes. Ele sugere que nós devemos adicionar àquelas duas orientações sociológicas opostas mais duas, diferentes daquelas, mas que compartilham com elas determinados componentes. A sociologia para políticas públicas estudaria processos de tomada de decisão, identificaria ações involuntárias ou inconscientes e ofereceria sua crítica à ideia segundo a qual nós somos determinados por nossa posição num sistema hierárquico. A sociologia pública é, por sua vez, a penetração da sociologia profissional no espaço público, para que suas descobertas possam ser aplicadas em apoio a certos valores e interesses.

Sem dúvida, muitos comentadores haverão de estudar a relação entre esses quatro setores do pensamento sociológico. Mas eu prefiro usar minha própria situação como um estrangeiro, como um forasteiro que elabora seus próprios conceitos, ao aproveitar elementos provenientes da vida intelectual europeia, estadunidense e latino-americana. A partir dessa perspectiva privilegiada, leio essas propostas tão criativas de um ponto de vista algo diferente. Porém, desde o início, declaro que aceito as principais orientações da análise de Burawoy (2005). Em vez de considerar a relação de oposição ou o relacionamento de complementaridade entre a sociologia pública e a sociologia profissional, como diferentes modalidades de conhecimento, eu me concentrarei em diferenças teóricas que existem entre as principais orientações da pesquisa sociológica, considerando, entretanto, que tais ideias são afetadas por diferenças nas situações históricas e culturais sob as quais vivemos.

Meu ponto de partida é que os atuais temas de pesquisa da sociologia não correspondem mais à sua definição “clássica”. Desde Émile Durkheim $(1947 ; 1967)$ até Talcott Parsons $(1977 ; 1991)$ e seus discípulos, aquilo que nós chamamos de sociologia clássica tem sido definida como o estudo dos processos pelos quais a sociedade é integrada, repele aqueles que considera seus inimigos e controla seus conflitos internos e processos de mudança. É fácil ver que as sociedades “fortes" e estáveis são mais fácil e frequentemente analisadas por essa linha teórica, ao passo que esse tipo de análise torna-se mais complicado em sociedades duais - aquelas que são dependentes ou colonizadas, que estão em crise aguda ou sob invasão externa, fragmentadas ou divididas por conflitos culturais ou mesmo sociais. Tais sociedades são mais sensíveis à seguinte oposição: por um lado, sua situação e seus processos sociais básicos são vistos como fortemente controlados a partir de fora - a conhecida globalização. Por outro, sua população é definida principalmente em termos culturais, religiosos, étnicos. Isso produz uma inadequada correspondência entre essas duas formas de análise e, com isso, nós ficamos com situações descritas não-socialmente e populações definidas não-socialmente.

Tal situação corresponde às experiências de muitos dentre nós; ela torna necessário que definamos a sociologia como a pesquisa de processos de ação social ou política que procuram preencher a lacuna entre as situações e as representações que temos delas. A sociologia, portanto, não se define mais como o estudo da sociedade ou dos sistemas sociais gerais, mas, antes, como o estudo dos processos sociais por meio dos quais os determinantes econômicos e políticos, de um lado, e os atores individuais ou coletivos, definidos cultural e socialmente, por outro, possam ser ligados, dando origem à ação coletiva, a processos políticos e a atitudes pessoais ou grupais.

A sociologia "clássica", em todo o caso, vem sendo demolida por ataques oriundos de várias frentes. Durante os últimos cinquenta anos, dois tipos de ataques têm sido especialmente perigosos e destrutivos. O primeiro deles vem do capitalismo triunfante, quer dizer, da dissolução dos controles sociais e políticos que regulavam a vida eco- 
nômica. Esse é o significado real da globalização: o mundo econômico não pode mais ser controlado por nenhuma autoridade política - seja nacional, seja regional-nem por protestos coletivos.

O segundo ataque vem do interior da própria sociologia. A organização da sociedade não é mais analisada em termos de funcionalidade ou disfuncionalidade, mas, antes, como um conjunto de processos por meio dos quais um aparelho de dominação insidioso controla todos os aspectos ou iniciativas da vida social, incluindo aí nossas próprias representações. Michel Foucault (1975; 2004) continuará sendo o mais original pensador a interpretar muitas instituições e categorias sociais a partir desse ponto de vista. Nós devemos acrescentar a essa crítica interna da sociologia clássica a emergência ou o crescimento de certos grupos - morais, religiosos, étnicos - que não poderiam ser reduzidos às suas funções sociais.

Em suma: atualmente, a sociologia é invadida por estudos de processos e mecanismos de “dessocialização" e “desinstitucionalização”, para os quais uma boa parte daquela sociologia tradicional, como campo de ensino e de pesquisa, tem perdido terreno - como nós podemos observar facilmente nas maiores livrarias, onde os estudos culturais e, em especial, as pesquisas sobre relações de raça e de sexo e, sobretudo ultimamente, os estudos a respeito dos gays e das lésbicas têm aumentado sua presença nas prateleiras.

Paralelamente, a sociologia radical, que era baseada na explicação da conduta coletiva por fatores não-sociais, pela natureza do capitalismo, da colonização ou da sociedade "patriarcal", oferecenos hoje cada vez menos análises originais e - mais importante ainda -tem se limitado à tarefa de revelar formas de repressão, de crueldade e discriminação totalmente invisíveis ou apenas parcialmente visíveis. Por fim, a pesquisa mais interessante é aquela que vem demonstrando o enfraquecimento ou o desaparecimento das modalidades tradicionais de sociabilidade, de normas sociais, de juízos morais, com o contínuo avanço de todas as formas de individualismo ou de subjetivismo. Essas conclusões negativas podem corroborar as categorias de Burawoy (2005).

Nem fatores culturais, nem fatores econômicos determinam inteiramente a vida social. Atores que vêm buscando se vincular à economia mundial, com suas culturas específicas, manifestam-nas de uma forma cada vez mais ativa. Estudálas é a principal tarefa da sociologia pública. Esse campo ainda está aberto ao estudo, com exceção dos casos-limite, em que forças impessoais, econômicas, militares ou valores e práticas alheias à cultura encontram-se completamente separados fato que corresponde ao choque entre civilizações descrito por Huntington (1996) A nova sociologia crítica estuda particularmente a transformação dos valores morais sob governos autoritários. Mas, para além dessa abordagem crítica, que se refere à contradição fundamental entre a lógica indestrutível da dominação e a ação enganosamente determinada subjetivamente, é necessário substituir o novo princípio de orientação axiológica pela ideia de sociedade, a qual vem sendo demolida.

Nós estamos acostumados a definir esse princípio em termos de "direitos naturais" ou movimentos por libertação; ou ainda em termos de consumação ou conformidade com alguma mensagem divina e coisa que o valha. O que é novo, em nossa situação, é que todos os princípios transcendentais têm sido abandonados por sociedades que podem se refazer ou se destruir totalmente. Isso torna necessário irmos além das maneiras anteriores de legitimação de "direitos" e reconhecer que o direito básico de qualquer indivíduo é ser considerado um "sujeito de direitos". Como um sujeito de direitos, uma pessoa ou uma categoria tem o direito não apenas de defender sua identidade - uma formulação que é perigosamente unidimensional -, mas também de ser um ator livre e responsável em seu relacionamento com o ambiente-ambiente sempre saturado de relações de poder. Esse "sujeito" pode ser constituído de uma forma tanto negativa e destrutiva como positiva e inclusiva. Ele pode se definir como uma raça, como o representante de um Deus, como uma elite, e de muitas outras formas que recusam ou destroem os direitos das outras pessoas. Isso aconte- 
ce quando um indivíduo ou categoria reivindica ter o monopólio da subjetividade significativa. Esse é o caso dos movimentos comunitários quando se recusam a se subordinar àqueles direitos individuais e universais que são expressos, em particular, pelo conceito de cidadania. Essa observação permite que nos livremos, em boa hora, da crítica superficial, segundo a qual a noção de sujeito é "moralista" e constitui uma ideologia que encoraja o conformismo e o conservadorismo.

Mas o significado verdadeiro daquele sujeito é exatamente o oposto. Ele mobiliza princípios universais contra todas as formas de ordem e de poder. É verdade que a noção de sujeito pode ser facilmente transformada em armamento para que elites autoritárias reivindiquem para si mesmas o monopólio da defesa dos direitos políticos, sociais e culturais. Pois, para além das reivindicações por cidadania, o terror se faz presente, e por trás da defesa dos direitos dos trabalhadores, escondese o perigo de uma ditadura que se imponha em nome do proletariado.

A sociologia não pode ser definida sem a explícita referência a "direitos" que resistam a todas as formas de dominação e de exploração. Essa declaração corresponde ao que Burawoy (2005) denomina "a dimensão reflexiva da sociologia". Com efeito, a matéria-prima básica da sociologia é o estudo de todas as formas de resistência às transações e instituições carregadas de poder. Nós não podemos definir a sociologia pública sem fazer referência direta ao reconhecimento dos direitos do sujeito, os quais são, direta ou indiretamente, definidos pela oposição a todas as formas de dependência e de dominação.

O papel da sociologia pública foi particularmente importante na Europa após a Segunda Guerra Mundial e após o regime nazista. A sociologia ressurgiu, acima de tudo, como sociologia industrial, sob a liderança de Georges Friedman (1964), em vários países. Friedman criticou a ideologia da organização científica do trabalho e propôs que a análise sociológica se concentrasse no movimento dos trabalhadores, na consciência de classe e no já emergente processo de desorganização da chamada classe operária.
Esses atores sociais criaram novos tipos de instituição que protegem atualmente os indivíduos contra o Estado. A Suprema Corte Americana é o melhor exemplo de institucionalização dos direitos dos indivíduos e das categorias de se defenderem dos mercados, dos conglomerados financeiros e dos governos autoritários. Em sociedades onde os direitos civis básicos são respeitados, a defesa do poder de cada indivíduo respeitar os direitos e as liberdades das outras pessoas conduz a novos agrupamentos institucionais. Toda pessoa tem o direito de ser um "sujeito" considerado e reconhecido como tal. Esse é o resultado de campanhas, de protestos, de medidas jurídicas ou diferentes canais através dos quais os "direitos humanos" - não apenas em sua dimensão política, mas também social e cultural - são definidos e defendidos. Esse novo tipo de instituição social é o campo de atuação sobre o qual uma nova sociologia profissional ou clássica poderá ser erguida.

Essa rapida descrição do que é a sociologia confere um papel central à sociologia pública. Isso torna clara a diferença entre, por um lado, a sociologia pública e a sociologia para políticas públicas e, por outro, a sociologia crítica. É possível agora mostrar, em síntese, a representação da sociologia que eu proponho, comparando-a diretamente com o esquema que vem sendo proposto de uma forma mais detalhada por Burawoy (2005).

Éclaro que meu ponto de partida é o declínio da sociologia clássica, a qual se tem apresentado como sociologia profissional, mas sem o direito de fazê-lo, pois a relevância conferida ao critério profissional precisaria ser dada a todas as outras orientações da sociologia. Em consequência disso, a sociologia pública ocupa o lugar central, porque ela se constitui na busca por atores. A sociologia para políticas públicas e a sociologia crítica são duas orientações que se completam, mas ambas podem também ser consideradas como subprodutos da sociologia pública. Por fim, uma nova sociologia profissional aparece como o estudo de instituições que não estão mais dedicadas às necessidades dos sistemas sociais, mas sim à proteção dos indivíduos e grupos contra as forças sociais dominantes. 
Figura 1 - As transformações da sociologia contemporânea

\begin{tabular}{|l|l|}
\hline Sociologia "clássica", construída ao redor de ideias a respeito da sociedade, valores sociais e normas sociais \\
\hline $\begin{array}{c}\text { Ordem social reinterpretada como um aparelho de } \\
\text { dominação (globalização); declínio da sociologia } \\
\text { clássica }\end{array}$ & $\begin{array}{c}\text { Dessocialização da vida econômica } \\
\text { (Sociologia crítica) }\end{array}$ \\
\hline \\
\hline Autonomia dos atores sociais e transformação dos cientistas sociais em analistas e defensores destes atores sociais \\
\hline $\begin{array}{c}\text { Sociologia orientada para políticas públicas, } \\
\text { estudando a formação de atores e de processos } \\
\text { políticos }\end{array}$ & $\begin{array}{c}\text { Pensamento crítico atacando as novas formas de } \\
\text { dominação, especialmente as baseadas em } \\
\text { valores culturais }\end{array}$ \\
\hline \multicolumn{2}{|c|}{} \\
\hline
\end{tabular}

A sociologia pública não poderá ser reduzida à simples difusão das pesquisas profissionais, mesmo sendo verdade que a descoberta e o estudo dos problemas sociais precisam ser sempre integrados à "sociologia geral”. Hoje, a sociologia pública constitui-se a sociologia geral. Um exemplo que considero particularmente interessante é que os estudos sobre a mulher são parte essencial da sociologia geral de hoje, e não um campo de estudos especial e separado.

Dirigir-se a qualquer espécie de público é, acima de tudo, falar sobre "direitos", de uma forma que corresponda às capacidades e expectativas desses públicos. Ao mesmo tempo, isso não significa formular uma ideologia que seja congênita aos interesses e valores dos públicos. A sociologia torna clara a presença, numa dada situação e para determinada categoria de indivíduos, de uma disputa em torno de direitos. Afinal de contas, a sociologia estuda o comportamento normativamente orientado.
A importância relativa de cada uma das quatro orientações da sociologia depende, em grande medida, do grau de autonomia dos atores sociais face às estruturas políticas, de um lado, e face à sua nova atribuição defensiva, por outro. Mas não podemos fechar as fronteiras entre as diferentes situações históricas e geográficas, porque podemos encontrar, em outros lugares, exemplos do quão alto ou do quão baixo é o nível de autonomia dos atores sociais.

Quanto mais afastados estivermos de uma onipotente concentração de poderio político, cultural e econômico, tanto mais sentiremos que uma crescente distância separará a economia global da nova vida comunitária local. Com isso, numa situação como essa, é menos provável que os atores políticos e sociais possam se organizar. Em muitos casos, um confronto direto entre forças econômicas e valores culturais obrigará a sociologia profissional a se identificar com a sociologia crítica.

Nessa situação extrema, há o risco de uma 
autodestruição da sociologia, pela qual proclamaremos que não restará mais espaço para os atores sociais, espremidos entre as todo-poderosas forças econômicas e aquelas culturas dominadas e na defensiva. Desde a queda da ideologia soviética e de seu regime, especialmente na Europa Central e Oriental, tem sido extremamente difícil erguer novas instituições e redefinir o campo das ciências sociais. O nacionalismo foi ali forte demais, e as restrições econômicas foram duras demais para que os atores sociais conseguissem desempenhar algum papel autônomo. Nos países "centrais", ao contrário, o perigo é levar muito a sério as normas instituídas e as estratégias de organização, sem fazer antes a sua indispensável desconstrução, desmascarando os processos de dominação que se escondem por trás do nacionalismo. Nas situações intermediárias, que correspondem à maioria dos casos na Europa, a sociologia para políticas públicas é mais ativa; e a maioria dos sociólogos transformou-se em "conselheiros do príncipe-regente", abandonando a pesquisa profissional.

Em inúmeras situações na América Latina, não é raro observar a convergência entre a sociologia para políticas públicas e a sociologia radical. $\mathrm{O}$ risco aqui é de se eliminar a sociologia profissional, e essa solução foi empregada com frequência nos primeiros anos da Guerra Fria. Esse perigo tem diminuído desde então, mas ainda se observa a forte tendência de se misturarem pesquisas orientadas para políticas públicas (e mesmo a sociologia crítica), numa condenação indiscriminada de condições que não são, entretanto, seriamente analisadas.

Uma conclusão otimista afirmaria - uma vez que a velha definição da sociologia como o estudo dos sistemas sociais foi abandonada - que, então, todos os tipos de sociologia poderiam ser considerados parte de uma sociologia geral dos atores, quer dizer, parte de uma sociologia pública. Uma consequência dessa definição de sociologia é que um grande número de estudos que descrevem e analisam situações - com frequência, em termos quantitativos, mas, às vezes, em termos históricos também - não deverá ser considerado como parte da sociologia, mesmo quando sua qualidade e uti- lidade forem reconhecidas. Isso corresponde à evolução que tem recolocado gradualmente, dentro da análise econômica e, acima de tudo, dentro das instituições de pesquisa econômica, um grande número de estudos que são mais cuidadosamente empreendidos por economistas, os quais, por sua vez, incorporam cada vez mais fatores sociais e culturais em suas análises.

Eu considero extremamente positivo que Burawoy (2005) defina o campo da sociologia como uma combinação entre quatro orientações básicas, que são muito mais do que simples empreendimentos complementares - como sistemas de produção e suas aplicações e difusão - porque seu esquema corresponde a componentes importantes da sociologia do conhecimento. O que torna difícil um acordo estável é que cada tipo de pesquisa sociológica está fortemente conectada tanto à história nacional, cultural e política do país como a certa divisão do trabalho intelectual que influencia a representação da sociologia e suas fronteiras com as ciências sociais vizinhas.

De uma forma muito mais concreta, as condições de circulação do conhecimento impõem grandes dificuldades à comunicação real. A concentração de um grande número de livros e outras publicações nos Estados Unidos e em Londres, devido à necessária existência de uma língua internacional, pode dar a impressão equivocada de um alto grau de consenso profissional. Isso cria a impressão de queé impossível a comunicação entre a maioria e as minorias e-o que é ainda mais grave-que os resultados das pesquisas e as ideias que são publicadas em outros idiomas merecem ser ignoradas, porque, afinal, só os melhores estudos acharão seu caminho numa tradução para o inglês. Malgrado o fato de que, atualmente, um número maior de sociólogos possui um entendimento muito mais amplo do que antes sobre o que vem acontecendo em outros domínios culturais, em minha opinião, nós ainda vivemos num universo intelectual que parece ser mais dividido por conflitos e contradições do que realmente é. Eis a razão pela qual eu considero a iniciativa de Burawoy (2005) muitíssimo importante, independentemente dos seus efeitos diretos. 
A situação atual é certamente muito melhor que durante a Guerra Fria, quando a sociologia era condenada e reprimida em vários países onde a ideologia, em sua forma mais brutal, dominou e destruiu a pesquisa sociológica e onde a assim chamada sociologia acadêmica foi tacanha ou incapaz de perceber os conflitos e processos de mudança na sociedade.

Uma das principais condições para alcançarmos um alto grau de comunicação - tanto em âmbito nacional como mundial - é dando prioridade à sociologia pública. Entendo por sociologia pública as observações, análises e interpretações que são mais diretamente relacionadas à vida social, como podemos observar (particularmente, mas não exclusivamente) naquelas pessoas que desejam modificar as práticas sociais ao descobrirem novas formas de deliberação e de organização. Em alguns momentos a demanda por teorização é mais urgente; já em outras épocas, a crítica social tem prioridade. Poderíamos considerar que, hoje, nós estamos muito longe da compreensão de várias formas de comportamento, e que nossa tarefa mais urgente é aumentar a qualidade do trabalho de campo. Mas esse trabalho de campo deve ser cada vez mais diretamente comparativo. E, se usarmos a expressão "sociologia pública" exatamente da maneira como Burawoy (2005) a emprega, então devemos estar dispostos a nos engajar com públicos que são exteriores à nossa própria sociedade. Essa não é uma tarefa simples. Precisamos reconhecer que, quando uma pessoa, pertencente à determinada cultura, estuda outra cultura, seus resultados geralmente são rejeitados como inadequados pelo povo ao qual a pesquisa diz respeito - mesmo quando se reconhece a qualidade profissional desse estudo.

Ocaráter específico da situação estadunidense é que a ideologia oficial da sua sociedade é tão fortemente rejeitada pelos acadêmicos, a começar pelos professores e estudantes, que eles são os mais capacitados a descobrir novos aspectos da "realidade", a tomar parte em movimentos reformistas ou a converter as ciências sociais aplicadas em campanhas para resolver problemas sociais. Eu estou surpreso com o entusiasmo da juventude norteamericana nos dias atuais - entusiasmo que pode ser explicado por sua hostilidade às políticas do ex-presidente George W. Bush no país e ao redor do globo. Após tantos anos de extensas pesquisas a respeito das minorias, das questões de gênero ou das relações étnicas, eles começam a desfazer em pedaços a imagem oficial da sua sociedade harmoniosa. A intenção deles é mudar o mundo e, até mesmo, "mudar de vida". A população jovem mobilizou-se muito mais ativamente contra um governo que considerava nacionalmente reacionário e mundialmente agressivo.

Como observador estrangeiro, fiquei impressionado com o silêncio da opinião pública estadunidense, especialmente dos círculos acadêmicos, quando o ex-presidente Bush decidiu atacar o Iraque sem qualquer consideração às instituições multilaterais criadas pelos próprios Estados Unidos. Dois anos mais tarde, fiquei novamente surpreso com a grande diversidade de projetos elaborados por jovens sociólogos para mudar sua sociedade. Essas pessoas estão tão profundamente comprometidas com questões políticas e sociais, que seus projetos de pesquisa são, ao mesmo tempo, projetos políticos. Suas visões alternativas da sociedade são baseadas em resultados acumulados pela sociologia profissional das últimas duas ou três gerações.

Se quiséssemos resumir essas observações, poderíamos dizer que a sociologia é mais frequentemente uma sociologia pública que uma sociologia para políticas públicas. Isso pode ser útil para traçarmos rápidas comparações com situações distintas.

A história das ciências sociais na Europa é bem diferente do caso estadunidense. Os cientistas sociais europeus desenvolveram fortes vínculos com os que formularam e implantaram políticas públicas durante o período pós-guerra, em especial junto a burocratas e sindicatos industriais. A França foi um bom exemplo da cooperação entre os cientistas sociais e a elite do funcionalismo público, os quais compartilhavam visões gerais sobre a sociedade. Governos fracos foram incapazes de elaborar e executar planos de longo prazo, 
mas seus melhores funcionários públicos e intelectuais elaboraram, conjuntamente, projetos cientificamente fundamentados e politicamente orientados. Essa aliança desapareceu quando a reconstrução do pós-guerra, levada a cabo pelo Estado, foi interrompida pelas novas políticas liberais dos anos 1970. Os esforços realizados por ótimas equipes de especialistas e conselheiros (think tanks), como o Clube Jean Moulin e, mais tarde, a Fundação SaintSimon, obtiveram resultados limitados. Na Alemanha, vínculos mais fortes mantiveram unidos o Partido Social-Democrata e os intelectuais.

Se considerarmos nossa situação quatro décadas após o Maio de 1968, veremos que os estudantes europeus estão fortemente motivados a lidar com as grandes questões mundiais, enquanto os estudantes norte-americanos são atraídos para a sociologia pública. Isso porque hoje eles estão conscientes de que os Estados nacionais são cada vez menos capazes de controlar os principais processos de mudança.

A influência das ideias do marxismo estruturalista tem sido profunda e duradoura em certos países em que ele conduziu a violentas ações radicais. O resultado dessa participação radical em atividades clandestinas ou ilegais foi a rejeição a todo tipo de participação em processos políticos, de uma forma tal, que a análise sociológica tem sido aí seriamente dificultada. Nos países ex-comunistas, o balanço é ainda mais negativo, porque, durante certo tempo, os sociólogos foram compelidos a abandonar as ciências sociais para conseguir sobreviver. Na Europa Ocidental, após a queda do muro de Berlim, os sociólogos mostraram-se incapazes de elaborar projetos institucionais consistentes para a transformação dos países ex-comunistas.

A nova geração de sociólogos estadunidenses é muito mais comprometida que seus companheiros europeus com pesquisas moral e politicamente relevantes, porque os sociólogos europeus ficaram expostos demais e por muito mais tempo a ideologias fatalistas, as quais os convenceram de que nada podia ser feito contra esse mundo fortemente globalizado e submetido à hegemonia norte-americana. Mas esse é um problema que se deve a diferenças passageiras, e a nova geração vem encontrando, em toda a parte, seu caminho no trabalho de campo e em iniciativas que combinam, de diferentes maneiras, o compromisso moral com as habilidades profissionais.

Há uma diferença importante entre os dois lados do Atlântico. Estudos de gênero e críticas feministas têm alcançado um alto nível nos Estados Unidos, ao passo que, na Europa, encontramos pesquisas mais descritivas sobre a desigualdade e a violência, muitas vezes inspiradas por uma perspectiva geralmente marxista. A despeito da importância desses estudos para aqueles que implementam políticas públicas, eles têm feito avanços limitados para criar interpretações que possam alcançar o mesmo alto nível obtido nos Estados Unidos.

O caso da sociologia na América Latina é, em certo sentido, mais parecido com a situação estadunidense do que com a situação europeia. A derrocada da sociologia crítica, que se seguiu ao fim do mito cubano e das guerrilhas, é visível em toda parte, mesmo onde a influência de Hugo Chávez e Fidel Castro tenha ganhado terreno. Pelo contrário, a sociologia para políticas públicas é aí muito ativa. Todos os assessores do ex-presidente do Chile, Ricardo Lagos, eram sociólogos; e Fernando Henrique Cardoso, ex-presidente do Brasil, era ele próprio um eminente sociólogo. Em vários países, os sociólogos são bastante influentes, e algumas instituições das Nações Unidas, como a Conferência das Nações Unidas para o Comércio e o Desenvolvimento - UNCTAD, conferem papel relevante aos sociólogos, como reação à orientação fortemente econômica do Consenso de Washington, que vem sendo bastante rejeitado hoje. A sociologia pública é menos visível, exceto no México, onde o sistema político é bloqueado e onde a democracia comunitária é muito ativa. Mas a sociologia profissional não tem progredido tanto, pois muitos sociólogos latinos vivem no exílio, onde participam de atividades governamentais e não-governamentais. Nós podemos concluir, a partir dessa breve comparação, que a sociologia pública é mais forte nos Estados Unidos, ao passo que os 
sociólogos latino-americanos são mais frequentemente os conselheiros dos seus governantes.

Há alguns anos atrás, na França, ao final de uma longa campanha de debates públicos sobre o tema "universidade e sociedade", o resultado do encontro nacional votou um apoio à ideia de que a mesma importância deveria ser dada aos três tipos do conhecimento formalizado: a ciência básica, a ciência aplicada e a pesquisa engajada. Os cientistas da natureza manifestam com frequência a ideia de que as ciências sociais são tão importantes quanto qualquer outro campo de pesquisa científica, porque elas lutam contra "patologias" tais como o crime, o racismo, o desemprego, a desigualdade de oportunidades e assim por diante.

Mesmo que, em alguns lugares, a sociologia venha sendo banida, seu lugar na universidade é hoje muito maior do que foi há meio século atrás. Mas parece difícil introduzir a sociologia em campanhas que mobilizem a opinião pública. Os sociólogos radicais estão perdendo terreno mais rapidamente na América Latina e nos Estados Unidos do que na Europa. Nos Estados Unidos e no Reino Unido, a sociologia profissional mantém vínculos mais fortes com a economia e a ciência política, ao passo que, em países como a Alemanha, a França e a Itália, os vínculos da sociologia são mais fortes com a filosofia e a história.

Essas comparações demonstram a utilidade das categorias elaboradas por Burawoy. A diferenciação interna da sociologia precisa ser combinada com sua integração ou, pelo menos, com a influência recíproca dos quatro tipos principais de orientação sociológica. Nós temos ouvido, com bastante frequência, pessoas condenarem a debilidade empírica da sociologia radical, assim como temos ouvido pessoas criticarem a sociologia para políticas públicas, por ela ser, muitas vezes, empregada para defender interesses mesquinhos. Mas hoje a sociologia pública combina com facilidade o pensamento crítico com boas pesquisas empíricas. Seu papel central vem do fato de não acreditarmos mais em filósofos da história ou em doutrinas políticas, embora sintamos necessidade de identificar os principais "problemas sociais" do nosso tempo. Tal objetivo requer a combinação da sociologia pública com a sociologia profissional, ao passo que a sociologia radical e a sociologia para políticas públicas movem-se lentamente para direções opostas das principais tendências da sociologia. Mas não devemos nos esquecer de que a sociologia profissional é útil para a sociologia pública - não apenas porque ela lhe impõe regras metodológicas, mas, acima de tudo, porque a teoria social é baseada tanto em pesquisas empíricas como em análises mais teóricas, as quais são indispensáveis para descobrirmos em que setores da vida social a sociologia "comprometida" poderá, com sucesso, tornar clara a natureza dos problemas sociais e as condições de programas de reforma política e moralmente eficazes.

(Recebido para publicação em abril de 2009) (Aceito em julho de 2009)

\section{REFERÊNCIAS}

BURAWOY, Michael. For public sociology. American sociological review, v. 70, fev., p. 4-28, 2005.

DURKHEIM, Émile. Les régles de la méthode sociologique. Paris: Presses Universitaires de France, 1947.

La division du travail social. Paris: Presses Universitaires de France, 1967.

FOUCAULT, Michel. Surveiller et punir, naissance de la prison. Paris: Gallimard, 1975

Naissance de la bio politique, cours au collège de France 1978-1979, Gallimard Seuil, 2004.

FRIEDMAN, Georges. Le travail en miettes. Paris: Gallimard, 1964.

HUNTINGTON, Samuel P. The clash of civilizations and the remaking of world order, New York: Simon \& Schuster, 1996

PARSONS, Talcott. Social systems and the evolution of action theory. New York/London: Free Press, 1977. The social system. London: Routledge, 1991. 


\section{PUBLIC SOCIOLOGY AND THE END OF THE SOCIETY}

\section{Alain Touraine}

Beginning with the verification that sociological research doesn't correspond to its classic definition anymore and that, consequently, the academic community's moment to overcome the contradiction between professional sociology and critical sociology has arrived, the author discusses some central points of Burawoy's proposal concerning public sociology. With resource to experiences coming out of LatinAmerican, North American and European intellectual life, this paper makes an effort in relating public sociology to the more general political process of recognition of social actors' rights, capable of organizing the field inside which a "general sociology of the actors" can flourish and grow. This paper verifies that there are times in which the demand for teorization is more urgent; in other times, social critic has priority. And concludes that if the sociological community still asserts the need to identify the main contemporary social problems, then the combination of public sociology with professional sociology is ever more necessary.

KEYwORDS: sociology of knowledge, academic sociology, social rights, political actors, social critic.

\section{LA SOCIOLOGIE PUBLIQUE ET LA FIN DE LA SOCIETE}

\section{Alain Touraine}

C'est en partant du principe que la recherche sociologique ne correspond plus à sa définition classique et que par conséquent le moment est venu pour la communauté académique de dépasser la contradiction entre la sociologie professionnelle et la sociologie critique, que l'auteur aborde quelques points essentiels de la proposition de Burawoy à propos de la sociologie publique. En faisant appel à des expériences issues de la vie intellectuelle européenne, américaine et latino-américaine, ce travail essaie de faire le lien entre la sociologie publique et le processus politique plus ample de reconnaissance des droits des acteurs sociaux, capable d'organiser le domaine au sein duquel une "sociologie générale des acteurs" pourra s'épanouir et se développer. On en arrive à la constatation qu'il y a des périodes au cours desquelles la demande de théorisation est plus urgente alors qu'à d'autres époques la critique sociale est prioritaire. La conclusion est que, si la communauté sociologique affirme encore le besoin d'identifier les principaux problèmes sociaux contemporains, il est donc nécessaire de faire de plus en plus le lien entre la sociologie publique et la sociologie professionnelle.

Mots-CLÉs: sociologie de la connaissance, sociologie académique, droits sociaux, acteurs politiques, critique sociale.

Alain Touraine - É um dos sociólogos contemporâneos cujas obras têm tido grande impacto na Europa e na América Latina. Transita de uma "sociologia da ação" para a "intervenção sociológica”, estudando especialmente os movimentos sociais. Foi aluno da École Normale Supérieur-Fr. e doutorou-se em Letras em 1965. Foi diretor de estudos da École Pratique des Hautes Études - Paris, onde fundou os centros de pesquisa: Laboratoire de Sociologie Industrielle, transformado em 1970 no Centre d'Études des Mouvements Sociaux; e em 1981 o Centre d'Analyse et d'Intervenion Sociologique, que dirigiu até 1993. É autor de inúmeras obras de referência:La sociedad postindustrial (1969), Les sociétés dépendentes (1976), Le rétour de l'acteur (1984) e La parole et le Sang (1988); Critique de la Modernité (1992) entre outras. Seu último livro intitula-se Une Société des femmes (Ed. Fayard, 2006). 